Journal of Zhejiang University-SCIENCE B (Biomedicine \& Biotechnology)

ISSN 1673-1581 (Print); ISSN 1862-1783 (Online)

www.zju.edu.cn/jzus; www.springerlink.com

E-mail: jzus@zju.edu.cn

\title{
Correspondence:
}

\section{A great honor and a huge challenge for China: You-you TU getting the Nobel Prize in Physiology or Medicine}

\author{
Da YUAN ${ }^{1}$, Xue YANG ${ }^{2}$, Jun-chao GUO ${ }^{\dagger 1}$ \\ ${ }^{1}$ Department of General Surgery, Peking Union Medical College \\ Hospital, Chinese Academy of Medical Sciences \& Peking Union \\ Medical College, Beijing 100730, China) \\ ( ${ }^{2}$ Institute of Hematology \& Blood Diseases Hospital, Chinese \\ Academy of Medical Sciences \& Peking Union Medical College, \\ Tianjin 300020, China) \\ ${ }^{\dagger}$ E-mail: gjcpumch@163.com
}

http://dx.doi.org/10.1631/jzus.B1600094

Public excitement over the award of the 2015 Nobel Prize in Physiology or Medicine to the Chinese medical scientist You-you TU for the discovery of a herbal anti-malarial, may mislead the Chinese people into believing that traditional Chinese herbal medicine can be used to cure all disease without any adverse effects. The aim of this paper is to explain the advantages and disadvantages of herbal traditional Chinese medicine (TCM) objectively.

\section{Introduction}

It is a great honor that the Chinese medical scientist You-you TU won the Nobel Prize in Physiology or Medicine 2015 for discovering artemisinin, which has saved hundreds of thousands of patients with malaria all over the world. According to the WHO World Malaria Report 2014 (World Health Organization, 2014), "the mortality rate from malaria will decrease by $55 \%$ worldwide and $62 \%$ in the WHO African Region by 2013, if the annual rate of decrease over the past 13 years is maintained." In children under

\footnotetext{
${ }^{\ddagger}$ Corresponding author

(1D) ORCID: Da YUAN, http://orcid.org/0000-0003-0364-8788

(c) Zhejiang University and Springer-Verlag Berlin Heidelberg 2016
}

five years of age, the positive result is even more dramatic with a $61 \%$ decrease in mortality rate expected worldwide and a $67 \%$ decrease expected in the WHO African Region. According to the Nobelprize. org. Nobel Media AB (2015), more than ten thousand people have been saved each year and in Africa alone, artemisinin-derived drugs have been used by nearly 250 million patients. Since 2006, artemisinin-based combination therapies (ACTs) have been recommended by the WHO as the priority treatment for malaria and have been adopted as first-line treatments in 79 of 88 countries where Plasmodium falciparum is endemic (World Health Organization, 2015). Thus, the discovery of artemisinin is really a huge contribution to the world. However, the details of its discovery were fraught (Kong and Tan, 2015).

\section{Main points}

When news of the Nobel Prize spread to China, it provoked a sensation among Chinese scientists and the public. After all, it is the first time that a civilian from the People's Republic of China has won the prize since the founding of New China and the media have reported on this news almost every day since. Chinese citizens, being proud of this achievement, have started to consider that herbal TCM is really useful and may cure all diseases.

There is no question that TCM is effective in treating some diseases, but the assumption that it can cure all diseases is dangerous and will harm the credibility of TCM as part of the Chinese health system. In the past, many Chinese became sick after consuming herbal TCM at unsafe doses or when treated inappropriately: previous cases related to aristolochic acid-induced nephropathy; more recently 
herbal hepatitis has come into focus. Another problem occurs when patients of some informal clinics are prescribed by doctors who do not even have a TCM license, leading to improper diagnosis and treatment.

Generally speaking, Chinese medicine is a gift to the world, but its disadvantages as well as its advantages must be considered. TCM can cure diseases for which effective western treatment is not available, for example kidney disease (Zhong et al., 2015), but if not used properly, it can lead to serious health problems. Wang et al. (2009) have discussed in detail aspects of the efficacy, safety, and quality of herbal TCM, but more evidence-based clinical trials are required to evaluate the benefit:risk ratio of herbal TCM (Teschke and Eickhoff, 2015). The China Food and Drug Administration (CFDA) has made progress in pharmacovigilance and risk control, taking into account the toxicology of Chinese herbal products (Shaw, 2010; Zhang et al., 2012).

The intention of this paper is to make recommendations to Chinese consumers and the Chinese government by taking Chinese a look at some common adverse reactions associated with the use of herbal TCM. Several herbs have been reported to have hepatic, renal, and gastrointestinal toxicities, but this is just the tip of the iceberg (Shaw, 2010; Teschke et al., 2014; Nyirimigabo et al., 2015). According to research from 1949 to 2006 provided by Li (2007), among 12354 cases describing side effects, 153 deaths were associated with the use of 158 different types of herbs. Many other cases, or even deaths, probably went unreported.

\subsection{Hepatotoxicity}

Herb-induced liver injury (HILI) is one of the most common adverse effects caused by TCM. This has been reported in many countries around the world including China (Taiwan region and the mainland), Japan, and Korea (US National Library of Medicine, 2014). According to Teschke et al. (2014), altogether 18 classifiable herbal mixtures and 39 individual herbs that are used to cure flu and colds have been reported to cause potential hepatotoxicity. The liver damage usually presents with symptoms such as fatigue, nausea, vomiting, and dark urine. If no effective actions are taken, the clinical outcome can be severe and even leads to acute liver failure with risk of death or the requirement for a liver transplant. Some of the toxicities associated with herbal TCM are well under- stood or documented: Wang et al. (2015) have described an experiment that proved kudzu root extractinduced hepatotoxicity; an experiment in rats showed that yuanhuapine-induced intestinal and hepatic toxicities were correlated with disturbance of amino acid metabolism, lipid metabolism, carbohydrate metabolism, and gut microflora (Chen et al., 2015); and, from 1992 to 2015, 693 cases have been reported for Chinese herbal hepatotoxicity (Teschke et al., 2015). Hepatotoxicity by herbal TCM must be validly established using a causality assessment method that is specific for the liver and hepatotoxicity such as Roussel Uclaf Causality Assessment Method (RUCAM) (Danan and Teschke, 2016).

\subsection{Nephrotoxicity}

Physicians from the US published the first case of kidney failure relating to traditional Chinese herb use in 1993 (Izumotani et al., 1993). Subsequently, aristolochic acid nephropathy was reported in Belgium in 2008 (Debelle et al., 2008). Nephrotoxicity caused by herbs has received wide spread attention, and some countries have even banned these herbs. According to a recent review, several types of molecule can cause renal injury, including aristolochic acid, alkaloids, anthraquinones, flavonoids, and glycosides (Xu et al., 2016). The mostly normal Chinese herb, tanshinol (Danshen), shows low propensity to cause renal transporter-mediated herb-drug interactions (Jia et al., 2015). Experiment has shown that Zexie may cause nephrotoxicity (Zhao et al., 2011). Radix Aristolochice and Radix Inulae not only cause kidney and liver damages, but also cause gastric cancer in rats (Qiao et al., 2007). Renal toxicity, which accounts for a large fraction of toxic events, deserves urgent public and clinical attention.

\subsection{Others}

Contact dermatitis is the most common adverse reaction observed following the use of herbal TCM in the US (Sen et al., 2010). Allergy is another, but less frequent, including allergic shock, asthma, and rhinitis, which are mostly caused by injection (Izumotani et al., 1993). As the quality of herbal medicines is related to climate, soil, and other growing conditions, and prescriptions are often for more than one herb, the pharmacological activity and toxicity of a particular treatment (such as pesticides and heavy metals (Efferth and Kaina, 2011)) cannot be guaranteed. 


\section{Discussion}

Most adverse events emerge if TCM is not used properly, while used correctly, it can cure some diseases effectively. The systematic analysis about Chinese medicinal materials reported by Chan (2005) has not attracted enough attention in China or western countries. Wang et al. (2009) suggested that Chinese herbal medicine should be investigated and evaluated according to the principles by which it has been developed over a few thousand years. Today, we have the capability of exploring the essence of TCM with wisdom using modern medical technology. This is a great opportunity for the Chinese government to promote herbal TCM to prosperity. Only if the government controls the medicine and drug market, uses available policies to encourage the advancement of the Chinese medicines industry, and guides the public in applying herbal TCM rationally, can we promote research into TCM.

Using medicinal drugs just once inappropriately may turn pharmacological effect into toxicity. Currently, many unsolved questions remain in the field of herbal TCM, but its advantages are obvious and require further elucidation by supporting studies. The purpose of this paper is to help the public, especially the people of China, to realize that TCM is not a drug to the disease. It must be used properly. Only in this way can we reduce the rate of adverse effects and improve the health of patients. Otherwise, many patients with liver and/or kidney damage and/or failure may emerge. This would be a disaster to patients and their families and a tremendous financial burden to the country and its health system.

\section{Compliance with ethics guidelines}

Da YUAN, Xue YANG, and Jun-chao GUO declare that they have no conflict of interest.

This article does not contain any studies with human or animal subjects performed by any of the authors.

\section{References}

Chan, K., 2005. Chinese medicinal materials and their interface with Western medical concepts. J. Ethnopharmacol., 96(1-2):1-18.

Chen, Y., Duan, J.A., Guo, J., et al., 2015. Yuanhuapineinduced intestinal and hepatotoxicity were correlated with disturbance of amino acids, lipids, carbohydrate metabolism and gut microflora function: a rat urine metabonomic study. J. Chromatogr. B, in press.

http://dx.doi.org/10.1016/j.jchromb.2015.08.024
Danan, G., Teschke, R., 2016. RUCAM in drug and herb induced liver injury: the update. Int. J. Mol. Sci., 17(1):14. http://dx.doi.org/10.3390/ijms17010014

Debelle, F.D., Vanherweghem, J.L., Nortier, J.L., 2008. Aristolochic acid nephropathy: a worldwide problem. Kidney Int., 74(2):158-169. http://dx.doi.org/10.1038/ki.2008.129

Efferth, T., Kaina, B., 2011. Toxicities by herbal medicines with emphasis to traditional Chinese medicine. Curr. Drug Metab., 12(10):989-996. http://dx.doi.org/10.2174/138920011798062328

Izumotani, T., Ishimura, E., Tsumura, K., et al., 1993. An adult case of Fanconi syndrome due to a mixture of Chinese crude drugs. Nephron, 65(1):137-140.

Jia, W., Du, F., Liu, X., et al., 2015. Renal tubular secretion of tanshinol: molecular mechanisms, impact on its systemic exposure, and propensity for dose-related nephrotoxicity and for renal herb-drug interactions. Drug Metab. Dispos., 43(5):669-678. http://dx.doi.org/10.1124/dmd.114.062000

Kong, L.Y., Tan, R.X., 2015. Artemisinin, a miracle of traditional Chinese medicine. Nat. Prod. Rep., 32(12):1617-1621. http://dx.doi.org/10.1039/c5np00133a

Li, D., 2007. Literature review of eighty-five cases of allergy due to usage of traditional Chinese medicine. Fujian Zhongyiyao, 38(3):44-45 (in Chinese).

Nobelprize.org. Nobel Media AB, 2015. The Nobel Prize in Physiology or Medicine 2015-Press Release. Available from http://www.nobelprize.org/nobel_prizes/medicine/ laureates/2015/press.html [Accessed on Mar. 17, 2016].

Nyirimigabo, E., Xu, Y.Y., Li, Y.B., et al., 2015. A review on phytochemistry, pharmacology and toxicology studies of Aconitum. J. Pharmacy Pharmacol., 67(1):1-19. http://dx.doi.org/10.1111/jphp.12310

Qiao, H.X., Liu, Y.Y., Wu, L.M., et al., 2007. Nephrotoxicity of Radix Aristolochice and it's substitution material Radix Inulae in rats. China J. Chin. Mater. Medica, 32(19): 2048-2051 (in Chinese).

Sen, P., Ho, M.S., Ng, S.K., et al., 2010. Contact dermatitis: a common adverse reaction to topical traditional Chinese medicine. Int. J. Dermatol., 49(11):1255-1260. http://dx.doi.org/10.1111/j.1365-4632.2010.04497.x

Shaw, D., 2010. Toxicological risks of Chinese herbs. Planta Med., 76(17):2012-2018. http://dx.doi.org/10.1055/s-0030-1250533

Teschke, R., Eickhoff, A., 2015. Herbal hepatotoxicity in traditional and modern medicine: actual key issues and new encouraging steps. Front. Pharmacol., 6:72. http://dx.doi.org/10.3389/fphar.2015.00072

Teschke, R., Wolff, A., Frenzel, C., et al., 2014. Review article: herbal hepatotoxicity - an update on traditional Chinese medicine preparations. Aliment. Pharmacol. Ther., 40(1): 32-50. http://dx.doi.org/10.1111/apt.12798

Teschke, R., Wolff, A., Frenzel, C., et al., 2015. Herbal traditional Chinese medicine and its evidence base in 
gastrointestinal disorders. World J. Gastroenterol., 21(15): 4466-4490.

http://dx.doi.org/10.3748/wjg.v21.i15.4466

US National Library of Medicine, 2014. Chinese and other Asian herbal medicines. Available from http://livertox. nih.gov/ChineseAndOtherAsianHerbalMedicines.htm [Accessed on Dec. 31, 2015].

Wang, D., Qiu, L., Wu, X., et al., 2015. Evaluation of kudzu root extract-induced hepatotoxicity. J. Ethnopharmacol., 176:321-326. http://dx.doi.org/10.1016/j.jep.2015.11.005

Wang, J.S., van der Heijden, R., Spruit, S., et al., 2009. Quality and safety of Chinese herbal medicines guided by a systems biology perspective. J. Ethnopharmacol., 126(1):31-41. http://dx.doi.org/10.1016/j.jep.2009.07.040

World Health Organization, 2014. World malaria report 2014. World Health Organization, p.16-18. Available from http://www.who.int/malaria/publications/world_malaria report_2014/en/ [Accessed on Apr. 27, 2016].

World Health Organization, 2015. Guidelines for the treatment of malaria, 3rd Ed. World Health Organization, Geneva, Switzerland. Available from http://apps.who.int/iris/ bitstream/10665/162441/1/9789241549127_eng.pdf?ua= $1 \& u a=1$ [Accessed on Sep. 10, 2015].

Xu, X.L., Yang, L.J., Jiang, J.G., 2016. Renal toxic ingredients and their toxicology from traditional Chinese medicine. Expert. Opin. Drug Metab. Toxicol., 12(2):149-159. http://dx.doi.org/10.1517/17425255.2016.1132306
Zhang, L., Yan, J., Liu, X., et al., 2012. Pharmacovigilance practice and risk control of Traditional Chinese Medicine drugs in China: current status and future perspective. $J$. Ethnopharmacol., 140(3):519-525. http://dx.doi.org/10.1016/j.jep.2012.01.058

Zhao, X., Lu, L., Zhang, Y., et al., 2011. Study on discriminating nephrotoxic components in Zexie. China J. Chin. Mater. Medica, 36(6):758-761 (in Chinese).

Zhong, Y., Menon, M.C., Deng, Y., et al., 2015. Recent advances in traditional Chinese medicine for kidney disease. Am. J. Kidney Dis., 66(3):513-522.

http://dx.doi.org/10.1053/j.ajkd.2015.04.013

\section{中文概要}

题 目: 荣誉与挑战: 论屠呦呦获得诺贝尔生理学或医学 奖对中国的影响

概 要: 中国首位诺贝尔生理学或医学奖获得者屠呦呦与 青蒿素的事迹引发对中医药的思考。在鼓励使用 中医药的同时，呼吁理性思考其不良反应，并对 相关临床问题进行阐述。对屠呦呦事迹的过度反 应，也许会误导国人对中医药产生 “包治百病而 无任何副作用” 的印象。为避免这种情况的出现, 本文客观地阐述其优缺点, 希望能够帮助国民理 性看待中医药。

关键词: 诺贝尔生理学或医学奖; 青蒿素; 中医药; 不良 反应 